\title{
Pengembangan Media Pembelajaran Berbentuk Power Point Interaktif Dalam Mata Pelajaran Pendidikan Agama Islam Kelas 1 Sekolah Dasar
}

\author{
1Dila Rukmi Octaviana, ${ }^{2}$ Moh. Sutomo, ${ }^{3}$ Moh Sahlan \\ ${ }^{123}$ Universitas Islam Negeri Kiai Haji Achmad Siddiq Jember \\ *E-mail : ${ }^{1}$ octavianadila920@gmail.com, ${ }^{2}$ sutomompd1971@gmail.com \\ 3mohsahlan@uinkhas.ac.id
}

\begin{abstract}
Abstrak
Media pembelajaran merupakan salah satu komponen terpenting dalam proses pembelajaran suatu pelaksanaan. Namun pada kenyataannya masih sedikit guru yang masih menggunakan media dalam proses pembelajaran, sehingga menurunkan hasil belajar siswa. Salah satu media pembelajaran yang paling sering digunakan yaitu media power point, media power point interaktif adalah media yang mudah dan bisa digunakan semua orang dan dapat divariasikan sesuai dengan kebutuhan siswa. Tujuan bertujuan untuk mendeskripsikan rancangan dan keefektifan media power point pada mata pelajaran pendidikan agama Islam. Jenis penelitian ini adalah Research and Development dengan menggunakan model penelitian 4D (Define, Design, Develop, Disseminate). Teknik analisis data dengan menggunakan kuantitatif dan kualitatif melalui angket. Subjek penelitian adalah $40 \%$ dari siswa kelas 1 SDN Sukowinangun 2 Magetan sebanyak 13 orang. Data yang diperoleh merupakan data kualitatif kemudian diubah menjadi data kuantitatif dengan menggunakan peoduct moment. Hasil penelitian menunjukkan bahwa media yang dikembangkan dinyatakan valid dengan persentase dari dua validator ahli sebesar $80 \%$ dan dari hasil evaluasi peserta didik sebesar $87 \%$.
\end{abstract}

Kata Kunci : Media Pembelajaran, Power Point, Siswa

\begin{abstract}
Learning media is one of the most important components in the learning process of an implementation. But in reality there are still a few teachers who still use the media in the learning process, thereby reducing student learning outcomes. One of the most frequently used learning media is power point media, interactive power point media is a medium that is easy and can be used by everyone and can be varied according to student needs. The aim is to describe the design and effectiveness of power point media in Islamic religious education subjects. This type of research is Research and Development using a 4D research model (Define, Design, Develop, Disseminate). Data analysis techniques using quantitative and qualitative through a questionnaire. The research subjects is 40\% from students were 13 students of class 1 SDN Sukowinangun 2 Magetan. The data obtained is qualitative data and then converted into quantitative data by using product moment. The results showed that the developed media was declared valid with a percentage of two expert validators at $80 \%$ and from the results of student evaluations at $87 \%$.
\end{abstract}

Keywords: Instructional Media, Power Point, Students 


\section{PENDAHULUAN}

Kurikulum Indonesia terus berubah dan berkembang mengikuti perkembangan zaman. Penerapan kurikulum 2013 masih memiliki beberapa kekurangan dan perbedaan dengan kurikulum sebelumnya. Salah satu kekurangannya adalah belum adanya media pembelajaran yang mendukung proses pembelajaran yang terintegrasi secara tematik dan sesuai dengan karakteristik siswa. Dengan adanya kekurangankekurangan tersebut, diharapkan guru yang profesional dapat mengembangkan dan menggunakan media pembelajaran unggulan yang sesuai dengan kebutuhan siswa, serta materi yang tersedia di Internet. Guru harus mampu merancang dan mendidik kemampuannya untuk memperoleh konten (materi) menggunakan teknologi untuk menciptakan pembelajaran yang menarik dan menghibur yang bermanfaat bagi siswa di era digital saat ini. Selain pengembangan teknologi, keterampilan khusus yaitu pemanfaatan teknologi oleh guru dalam proses pembelajaran (teknologi), juga diperlukan(Dewi and Manuaba 2021, 77).

Pendidikan merupakan suatu hal yang sangat berpengaruh dalam kemajuan suatu negara, selain itu pendidikan juga merupakan usaha untuk menciptakan suatu pembelajaran yang aktif, sehingga dapat mengembangkan potensi yang dimiliki suatu individu tersebut. Hal ini sesuai dengan Undang-Undang No. 20 Tahun 2003 Bab 1 Pasal 1 tentang Sistem Pendidikan Nasional yang dijelaskan bahwasanya pendidikan adalah usaha sadar dan terencana untuk mewujudkan suasana belajar dan proses pembelajaran agar peserta didik aktif mengembangkan potensi dirinya untuk memiliki kekuatan spiritual, pengendalian diri, kepribadian, kecerdasan, akhlak mulia, serta keterampilan yang diperlukan dirinya, masyarakat, bangsa dan negara.

Dalam konteks ini, peningkatan proses pembelajaran memerlukan media yang menarik yang membangkitkan semangat dan minat serta menyemangati siswa dalam proses kegiatan pendidikan dan pembelajaran di kelas. Alternatif pemecahan masalah yang baik adalah media pembelajaran interaktif berbasis Microsoft Power Point. Ini membantu Anda menggabungkan semua elemen media seperti teks, gambar, audio, bahkan video dan animasi menjadi media pembelajaran yang menarik. Bagi para pengguna komputer, Microsoft Power Point merupakan salah satu aplikasi yang banyak digunakan dalam aktivitasnya terutama saat memberikan presentasi. Microsoft Power Point adalah perangkat lunak yang membantu Anda membuat presentasi yang efektif, profesional, dan sederhana. Media Power point memudahkan kita merancang berbagai mahan presentasi visual yang menakjupkan menggunakan teks, foto, animasi, vidio dan kuis dalam penyajian presentasi kepada siswa. Dengan penyajian materi pendidikan agama Islam (PAI) menggunakan power point akan lebih menarik siswa untuk lebih mudah memahami pembelajaran (Suwartini n.d, 2021, 66)

Selama ini PowerPoint hanya digunakan sebagai media presentasi sepihak (noninteraktif) dimana siswa hanya berperan sebagai pendengar atau penonton tanpa terlibat aktif dalam proses pembelajaran. PowerPoint dengan hyperlink dan kemampuan suara yang dapat digabungkan untuk membuat presentasi multimedia interaktif. Kombinasi hyperlink dan slide memungkinkan Anda membuat presentasi interaktif yang memungkinkan siswa menggunakan strategi kognitif tingkat yang lebih tinggi.

Media dalam arti sempit berarti komponen bahan dan komponen alat dalam sistem pembelajaran. Dalam arti luas media berarti pemanfaatan secara maksimum semua komponen sistem dan sumber belajar di atas untuk mencapai tujuan pembelajaran tertentu. Menurut Hamidjojo yang dikutip oleh Mohamad Miftah yang dimaksud media ialah semua bentuk perantara yang dipakai orang penyebar ide, sehingga gagasan itu 
sampai kepada penerima. Sedangkan, Menurut Mc Luhan yang ikutip oleh Mohammad Miftah memberikan batasan yang intinya bahwa media sarana yang disebut saluran, karena pada hakekatnya media telah memperluas dan memperpanjang kemampuan manusia untuk merasakan, mendengar dan melihat dalam batas jarak dan waktu tertentu, kini dengan bantuan media batas-batas itu hampir menjadi tidak ada (Miftah 2013, 97-98)

Sedangkan, istilah pembelajaran atau pengajaran (ungkapan yang lebih banyak dikenal sebelumnya), adalah upaya untuk membelajarkan pebelajar. Membelajarkan berarti usaha membuat seseorang belajar. Dalam upaya pembelajaran terjadi komunikasi antara pebelajar (siswa) dengan guru, pembelajar atau pengajar (ungkapan yang lebih umum digunakan sebelumnya), sehingga proses pembelajaran seperti ini adalah sebagai bagian proses komunikasi antar manusia (dalam hal ini yaitu antara pembelajar dan pebelajar). Meskipun dapat saja terjadi komunikasi langsung antara pebelajar dengan bahan pembelajaran, di sana ada peranan media pembelajaran.

Jadi pengertian media pembelajaran secara singkat dapat dikemukakan sebagai sesuatu (bisa berupa alat, bahan, atau keadaan) yang digunakan sebagai perantara komunikasi dalam kegiatan pembelajaran. Jadi ada tiga konsep yang mendasari batasan media pembelajaran di atas yaitu konsep komunikasi, konsep sistem dan konsep pembelajaran.

Microsoft powerpoint merupakan aplikasi presentasi dalam komputer yang penggunaannya mudah, karena program powerpoint ini dapat diintegrasikan dengan microsoft lainnya seperti word, excel, access dan sebagainya. Power Point juga merupakan salah satu program di bawah microsoft office program komputer dan tampilan ke layar dengan menggunakan bantuan LCD proyektor. Pembelajaran menggunakan media Power Point ini dirancang untuk pembelajaran yang interaktif, dimana dalam media presentasi powerpoint dirancang dan dilengkapi dengan alat pengontrol yang dapat dioperasikan oleh pengguna sehingga pengguna dapat memilih apa yang dikehendaki untuk petunjuk penggunaan, materi, dan soal latihan (Andriani 2016, 145).

Power Point merupakan media yang menarik untuk menumbuhkan semangat, minat, serta mengaktifkan siswa dalam proses kegiatan belajar mengajar di kelas. Salah satu alternatif mengatasi masalah yang cocok yaitu dengan media pembelajaran interaktif berbasis Microsoft Power Point akan membantu dalam menggabungkan semua unsur media seperti teks, gambar, suara bahkan video dan animasi sehingga menjadi sebuah media pembelajaran yang menarik. (Anyan, Ege, and Faisal 2020, 16).

\section{METODE PENELITIAN}

Metode penelitian yang digunakan dalam penelitian ini adalah penelitian dan pengembangan (Research and Development). Model pengembangan yang digunakan dalam penelitian ini adalah model pengembangan yang dikemukakan oleh Thiagarajan, Semmel dan Semmel dimana tahapan penelitian pengembangan terdiri dari 4 tahap yang dikenal dengan model 4D yaitu:

a. Define instructional requirements. Pada tahap ini dilakukan analisis kebutuhan yang meliputi studi literatur dan survei lapangan.

b. Design prototypical instructional model.Tahap ini bertujuan untuk membuat model prototype. Kegiatan yang dilakukan meliputi merancang model, validasi pakar terhadap model prototype, dan penyempurnaan model prototype berbasis hasil validasi ahli. 
c. Develop tested and reliable instructional model. Tujuan dari tahap ini adalah untuk mengembangkan model pembelajaran beserta perangkatnya agar mendapatkan model yang valid, teruji dan reliable (dapat dipercaya).Kegiatan yang dilakukan adalah ujicoba terbatas.

d. Disseminate instructional model. Kegiatan yang dilakukan pada tahap ini adalah uji coba diseminasi dalam sampel yang lebih luas untuk mendapatkan perbaikan dan penyempurnaan. Tujuan akhirnya adalah untuk menghasilkan model yang valid dan teruji yang siap dipromosikan ke pengguna(Nursit, 2016, 41-43)

Teknik pengumpulan data yang digunakan dalam penelitian ini adalah angket, dan wawancara tidak terstruktur. Angket digunakan untuk mengetahui kebutuhan dan validitas Power Point, wawancara digunakan untuk mengetahui kualitas Power Point interaktif yang disusun. Instrumen penelitian berupa lembar validasi yang digunakan untuk mengetahui tingkat kevalidan dari media pembelajaran berupa Power Point tersebut. Penelitian ini menggunakan dua teknik analisis data, yaitu:

1) Teknik analisis deskriptif kualitatif untuk mengolah data hasil review dari dua orang validator ahli dan peserta didik.

2) Analisis statistik deskriptif untuk mengolah data yang diperoleh melalui angket dalam bentuk deskriptif persentase. (Dewi and Izzati, 2020, 219-220)

Data yang diperoleh dari lembar validasi dan angket respon adalah data ordinal. Oleh karena itu, untuk mengubah data ordinal menjadi data interval digunakan cara transformasi msr (method of summated ratings).

Analisis data menggunkan skala likert untuk menghitung tingkat kevalidan dari produk yang dibuat. Adapun rumus pengolahan data yaitu :

$$
\begin{array}{cl}
V=\sum \underline{X} \times 100 \% & \\
\mathrm{~N} & \\
\text { Keterangan : } V & =\text { nilai } \\
& \sum X \quad=\text { skor yang diperoleh } \\
N \quad=\text { skor maksimum }
\end{array}
$$

Untuk menentukan tingkat kategori valid atau tidaknya media pembelajaran yang dikembangkan untuk digunakan dalam pembelajaran digunakan kriteria kualifikasi penilaian yang ditunjukkan pada tabel berikut :

Tabel. 1 skala perhitungan validasi ahli

\begin{tabular}{cc}
\hline Skor & Kriteria \\
\hline 5 & Sangat Baik (SB) \\
4 & Baik (B) \\
3 & Cukup (C) \\
2 & Kurang (K) \\
1 & Sangat Kurang (SK) \\
\hline
\end{tabular}

Dengan kriteria ke validan sebagai berikut :

Tabel. 2 Kriteria Kevalidan

\begin{tabular}{lc}
\hline \multicolumn{1}{c}{ Penilaian } & Kriteria \\
\hline $80 \%<x \leq 100 \%$ & Sangat Valid \\
$60 \%<x \leq 80 \%$ & Valid \\
$40 \%<x \leq 60 \%$ & Cukup Valid \\
\hline
\end{tabular}




\begin{tabular}{lc}
$20 \%<x \leq 40 \%$ & Tidak Valid \\
$0 \%<x \leq 20 \%$ & Sangat Tidak Valid \\
\hline
\end{tabular}

\section{HASIL DAN PEMBAHASAN.}

a. Define instructional requirements (Analisis Kebutuhan)

Tahapan ini meliputi analisis Rancangan Pelaksanaan Pembelajaran (RPP), Analisis materi dan analisis kondisi peserta didik. Analisis Rancangan Pelaksanaan Pembelajaran (RPP) dari materi Bersih Itu Sehat pelajaran ke 4 Pelajaran Pendidikan Agama Islam dan Budi Pekerti ditemukan ada beberapa tujuan pembelajaran diantaranya adalah:

1) Mampu menyebutkan arti bersuci dengan benar.

2) Mampu menyebutkan macam-macam bersuci dengan benar.

3) Mampu mencontohkan tata cara mandi dan istinja' (buang air kecil dan besar) dengan benar.

4) Dapat menunjukkan tata cara mandi dan istinja' (buang air kecil dan besar) dengan benar.

5) Membiasakan bersuci sebelum beribadah dengan benar.

6) Menunjukkan perilaku bersih badan, pakaian, barang-barang, dan tempat dengan benar.

7) Membentuk karakteristik siswa yang Religius, Nasionalis, Mandiri, Gotong Royong, Integritas.

Analisis materi yang dipelajari oleh peserta didik adalah pelajaran Pendidikan Agama Islam dan budi pekerti pelajaran ke 4 yaitu bersih itu sehat terdiri dari 3 sub bab yaitu bersuci, macam-macam bersuci dan hidup bersih setelah dianalisis kiranya agar materi ini agar lebih menarik sehingga dapat mempergunakan Power Point interaktif sebagai media penunjang dalam pembelajaran.

Analisis kebutuhan siswa dari pengamatan yang dilakukan oleh peneliti menemukan beberapa kesulitan yang dialami peserta didik dalam memahami pembelajaran pendidikan agama islam dan budi pekerti diantaranya adalah:

1) Kurang tertariknya peserta didik apabila strategi belajar hanya berpaku dengan membaca buku saja sehingga mengakibatkan siswa kurang tetarik dan mudah bosan karena biasanya siswa kelas 1 Sekolah Dasar (SD) lebih suka dengan hal yang berbentuk gambar yang berwarna-warni atau vidio yang berbentuk animasi yang lucu.

2) Adanya kesulitan dalam memahami pelajaran karena ada sebagian siswa yang kurang lancar dalam membaca.

b. Design prototypical instructional model (Mendesain Media Pembelajaran).

Pada tahap ini peneliti mendesain media pembelajaran yang berbentuk Power Point interaktif, ada beberapa tahapan yang dilakukan pada tahap ini diantaranya menyiapkan media Power Point itu sendiri dan membaginya menjadi beberapa bagian diantaranya:

1) Pembuka meliputi halaman sampul, doa sebelum belajar, menu dan petunjuk penggunaan power point interaktif.

2) Kedua, bagian inti meliputi materi, pengisian tabel dan evaluasi hasil belajar (ayo berlatih)

3) Bagian penutup yang meliputi rangkuman dan halaman penutup. Selain itu sebenarnya dalam bagian ini terdapat 
Selain mendesain media pembelajaran pada tahap ini sebenarnya juga ada tinjauan dari para ahli terkait dengan desain, bahasa dan materi tekait dengan media pembelajaran yang telah dibuat melalui validasi angket.

Tabel 3. Presentase Hasil Validitas Power Point Interaktif Menurut Tinjauan Ahli

\begin{tabular}{ccc}
\hline $\begin{array}{c}\text { Subjek } \\
\text { Uji Coba }\end{array}$ & Hasil Validitas & Keterangan \\
\hline Uji Isi & $70,00 \%$ & Valid \\
Mata & & \\
Pelajaran & & Sangat Valid \\
Uji & $80,00 \%$ & \\
$\begin{array}{l}\text { Desain } \\
\text { Power } \\
\text { Point }\end{array}$ & \\
Uji tata \\
bahasa
\end{tabular}

Berdasarkan hasil validasi di atas, oleh validasi ahli materi memperoleh presentasi nilai sebesar 70\%, dimana nilai tersebut termasuk kedalam kategori valid dan bisa digunakan dengan sedikit revisi untuk menambahkan vidio terkait kata cara mandi dan istinja' dengan vidio yang sopan dan menarik untuk siswa, selanjutnya oleh validasi ahli desain memperoleh presentasi nilai sebanyak $80 \%$ yang memiliki tingkat kevalidan sangat baik sehingga bisa digunakan tanpa revisi. Berdasarkan kedua presentasi oleh validator tersebut, diperleh nilai rata-rata validator ahli sebesar $90 \%$. Berdasarkan hasil tersebut dapat disimpulkan bahwa media pembelajaran powerpoint intraktif ini bisa digunakan untuk uji coba tanpa revisi.

c. Develop tested and reliable instructional model.

Pada tahap ini dilakukan pembuatan media pembelajaran PowerPoint interaktif yang akan digunakan berdasarkan design pada tahap sebelumnya. Media pembelajaran PowerPoint intraktif ini meliputi :

1) Bagian pembuka

Pada bagian pembuka ini yang terdiri dari sampul, doa sebelum belajar, menu dan petunjuk penggunaan. Pada bagian sampul terdapat judul dan gambar anak-anak yang sedang bersih-bersih agar relevan dengan judul materi yang akan dibahas yaitu bersih itu sehat. Letak interaktifnya adalah adanya tobol mulai untuk memulai slide power point. Lalu dilanjutkan dengan slide kedua yaitu slide doa sebelum belajar karena kita tak lupa membiasakan agar anak-anak selalu berdoa dalam memulai segala hal. Selanjutnya dilanjutkan dengan petunjuk agar memudahkan para siswa mengoprasikan power point tersebut. Selanjutnya terdapat menu apa saja yang terdapat dalam power point ini dan apabila di klik dalam salah satu gambar atau pun shape dapat dimunculkan sesuatu yang kita tekan tersebut. Bagian pembuka ditampilkan sebagai berikut:

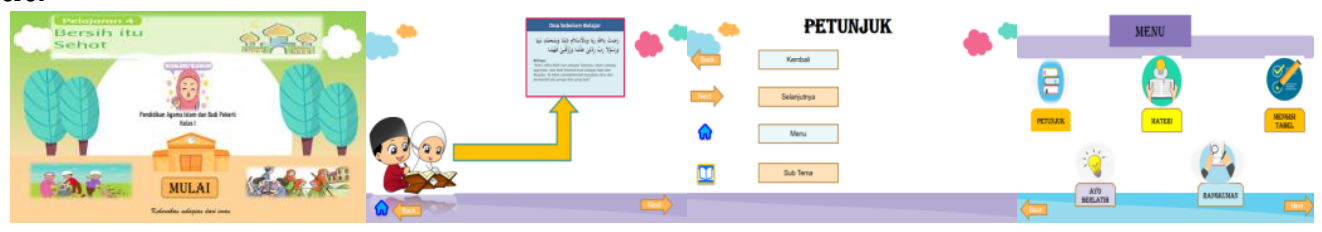

Gambar 1. (a) Cover; (b) Doa sebelum belajar; (c) Petunjuk; (d) Menu 
2) Bagian Inti.

Bagian inti ini terdiri dari materi, mengisi tabel dan evaluasi pemahaman siswa yang disebut ayo berlatih. Pada bagian matri terdapat sub materi apa saja yang akan dipelajari dalam materi bersih itu sehat dan kita bisa mengeklik materi mana yang akan dipelajari baik itu bersuci, tata cara bersuci maupun hidup bersih. Selanjutnya pada bagian tabel kita bisa melakukan interaksi dengan para siswa terkait dengan petanyaan apa saja yang terdapat pada tabel tersebut. Selanjutnya pada bagian evaluasi ada 5 soal pilihan ganda terkait dengan materi yang telah diajarkan kemudian siswa dapat memilih salah satu jawaban yang disediakan apabila jawaban salah akan muncul gambar menangis dan efek suara bom namun apabila jawaban benar akan muncul gambar tersenyum dan terdapat efek suara tepuk tangan. Bagian inti ditampilkan melalui Gambar 2.

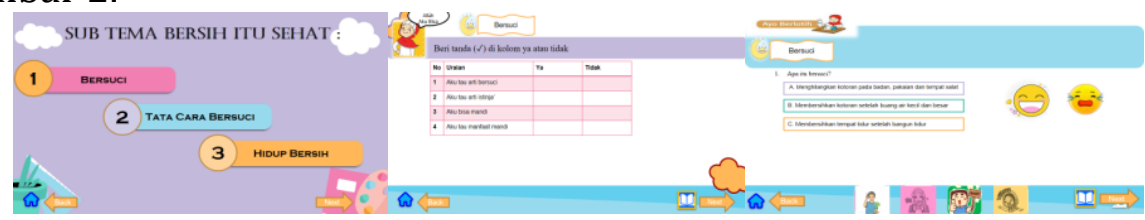

Gambar 2. (a) Sub tema materi (b) Mengisi tabel (c) Evaluasi ayo berlatih

3) Bagian penutup ini terdiri dari rangkuman dan halaman penutup. Pada bagian rangkuman terdiri dari rangkuman materi yang telah dipelajari agar siswa dapat mengulangi dan mengingat lag materi yang telah diajarkan, sedang dibagian terdapat ucapan salam yang bergerak dan kata-kata motivasi yang ditunjukan kepada siswa. Bagaian penutup dijelaskan melalui Gambar 3.

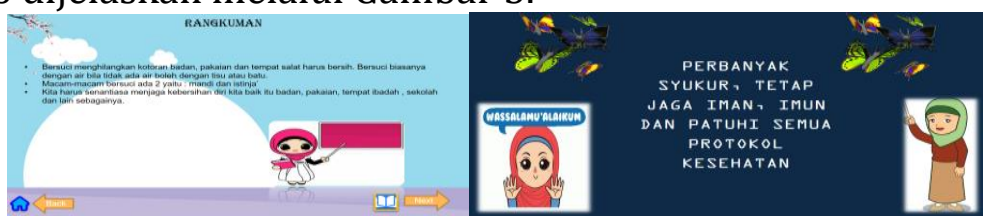

Gambar 3. (a) Rangkuman; (b) Halaman penutup.

Pada tahap ini juga dilakukan uji coba media power point interaktif ini kepada beberapa siswa yang meliputi beberapa tahap yaitu :

a) Tahap uji coba secara personal. Di ujicobakan kepada 3 siswa keefektifan pada saat diujikan secara personal sekitar $65 \%$ masih ada sedikit evauasi dalam power point khususnya pada sub tema bersuci yang hanya berbentuk tulisan berbagan saja. Pada hal ini siswa kurang memahami dengan jelas karena tidak ada gambar yang menjelaskan hal tersebut. Slide yang dievaluasi dijelaskan pada Gambar 4.

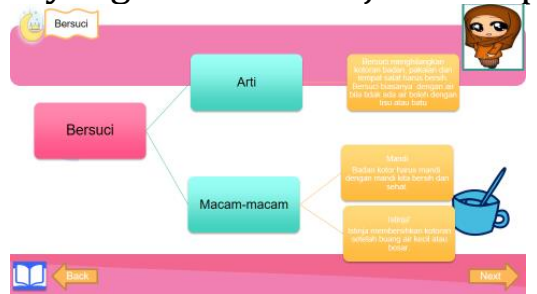

Gambar 4. Pengertian dan Macam-macam Bersuci.

b) Tahap uji coba secara kelompok kecil. Pada tahap ini di uji cobakan kepada 8 orang. Keefektifan sekitar $80 \%$ dan ketika tahap ini ada evaluasi terkait dengan evaluasi pembelajaran dirasa kurang efektif dan menarik karena hanya berbentuk soal biasa. Slide yang dievaluasi terdapat dalam Gambar 5.

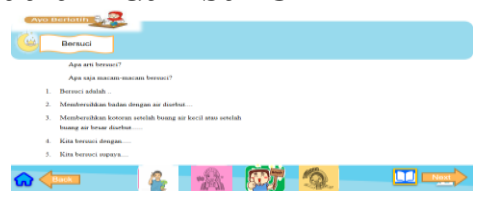




\section{Gambar 5. Soal evaluasi Bersuci}

c) Tahap uji coba secara kelompok besar. Pada tahap ini dilakukan ujicoba kepada 13 anak. Pemahaman siswa dalam tahap ini mencapai $87 \%$ sudah cukup efektif pembelajaran yang berlangsung hal ini didapatkan dari hasil evaluasi belajar.

d. Disseminate instructional model.

Kegiatan yang dilakukan pada tahap ini adalah uji coba diseminasi dalam sampel yang lebih luas untuk mendapatkan perbaikan dan penyempurnaan. Karena adanya keterbatasan waktu peneliti belum melaksanakan proses uji coba kepada objek yang lebih luas yaitu uji coba kepada kelas rill. Selain itu pada tahap ini juga dilakukan penyebarluasan media pembelajaran berbentuk power point interaktif kepada guru berbentuk soft file melalui jejaring whatsApp maupun email. Yang gunanya untuk mempermudah guru dalam menyampaikan pembelajaran pendidikan agama Islam khususnya pada materi pembelajaran "Bersih Itu Sehat" dan karena di power point ini dilengkapi dengan vidio juga menjadikan siswa lebih faham terkait dengan tata cara mandi dan Istinja. Selain itu dipower point ini dirancang untuk mempermudah siswa dalam memahami terkait dengan pengertian mandi dan istinja' yang dilengkapi dengan gambar karena disesuaikan dengan siswa kelas 1 sekolah dasar yang kadang belum terlalu lancar membaca.

Penggunaan media dalam pembelajaran sangat efektif digunakan guru dalam membantu siswa memahami pelajaran. Menurut Suttrisno (2021:80) penggunaan media atau alat peraga dapat membantu meningkatkan motivasi dan hasil belajar siswa serta dapat membantu meningkatkan kinerja guru.

\section{KESIMPULAN DAN SARAN}

Untuk meningkatkan proses pembelajaran diperlukan sebuah media yang menarik untuk menumbuhkan semangat, minat, serta mengaktifkan siswa dalam proses kegiatan belajar mengajar di kelas. Salah satu alternatif mengatasi masalah yang cocok yaitu dengan media pembelajaran interaktif berbasis Microsoft Power Point akan membantu dalam menggabungkan semua unsur media seperti teks, gambar, suara bahkan video dan animasi sehingga menjadi sebuah media pembelajaran yang menarik.

Proses pengembangan media power point ini menggunakan model 4D yang meliputi:

a. Define instructional requirements Define instructional requirements

b. Design prototypical instructional model

c. Develop tested and reliable instructional model.

d. Disseminate instructional model.

Kami selaku penulis artikel ini, memohon saran kepada berbagai pihak, dimana dalam penulisan artikel ini masih banyak sekali kesalahan dan kekurangan. Dalam penulisan materi ini kami mengambil referensi dari berbagai bahan baik itu cetak ataupun elektronik. Selanjutnya kami akan memperbaiki artikel ini agar jauh lebih baik lagi.

\section{UCAPAN TERIMAKASIH.}

Kami ucapkan banyak terimakasih kepada pihak yang telah membantu dalam penelitian ini yakni dosen pengampu mata kuliah Media pengembangan media berbasis IT bapak Dr. Moh Sutomo, M.Pd dan Bapak Dr. Moh Sahlan, M.Pd, kepala Sekolah SDN Sukowinangun 2 Magetan, Bapak/ibu guru serta siswa kelas 1 SDN Sukowinangun 2 Magetan. 


\section{REFERENSI.}

Andriani, Maria Resti. 2016. "Pengembangan Media Pembelajaran Power Point Interaktif Melalui Pendekatan Saintifik Untuk Pembelajaran Tematik Integratif Siswa Kelas 2 SDN Bergas Kidul 03 Kabupaten Semarang." Scholaria: Jurnal Pendidikan Dan Kebudayaan 6(1):143-157.

Anyan, Anyan, Benediktus Ege, and Hendry Faisal. 2020. "Pengembangan Media Pembelajaran Interaktif Berbasis Microsoft Power Point." JUTECH: Journal Education and Technology 1(1).

Dewi, Maharani Delta, and Nur Izzati. 2020. "Pengembangan Media Pembelajaran Powerpoint Interaktif Berbasis Rme Materi Aljabar Kelas Vii Smp." Jurnal Ilmiah Pendidikan Matematika 8(2):217-226.

Dewi, Ni Luh Putu Sintia, and Ida Bagus Surya Manuaba. 2021. "Pengembangan Media Pembelajaran Powerpoint Interaktif Pada Mata Pelajaran IPA Siswa Kelas VI SD." Jurnal Penelitian Dan Pengembangan Pendidikan 5(1).

Miftah, Muhammad. 2013. "Fungsi, Dan Peran Media Pembelajaran Sebagai Upaya Peningkatan Kemampuan Belajar Siswa." Kwangsan: Jurnal Teknologi Pendidikan 1(2):95-105.

Nursit, Isbadar. 2016. "Pengembangan Multimedia Interaktif Berbasis Power Point (Macro-Enabled) Pada Mata Kuliah Geometri Euclid Dalam Pembelajaran Matematika." Media Pendidikan Matematika 4(1):41-49.

Suttrisno, S. (2021). "Pengaruh Pemanfaatan Alat Peraga Ips Terhadap Kinerja Guru Sekolah Dasar". Jurnal Ilmiah Pendidikan Dasar, 8(1), 77-90.

Suwartini, Suwartini. n.d. "Upaya Meningkatkan Motivasi Dan Hasil Belajar Melalui Problem Based Learning Dengan Powerpoint Di Sekolah Dasar." Jurnal Riset Madrasah Ibtidaiyah 1(1):348-393. 